\title{
Analisando a temática experimentação no ensino de química no conteúdo de eletroquímica dos livros didáticos aprovados no PNLD 2015
}

\section{RESUMO}

Mateus Carneiro Guimarães dos Santos

$\frac{\text { mateus.dqi@live.com }}{\text { orcid.org/0000-0002-5859-0248 }}$ Orcid.org/0000-0002-5859-0248

Matheus Junior Baldaquim

matheusbaldaquim@gmail.com

orcid.org/0000-0001-7816-8709

Universidade Estadual de Maringá (UEM) Maringá, Paraná, Brasil

Luana Pires Vida Leal

luanapvidaleal@gmail.

orcid.org/0000-0002-2092-1400

Universidade Estadual de Londrina (UEL), Londrina, Paraná, Brasil
O seguinte trabalho teve como objetivo verificar e categorizar as atividades experimentais contidas nas seções do conteúdo de pilhas e baterias nos Livros Didáticos de Química aprovados no PNLD 2015. Adotamos o referencial teórico da análise de conteúdo de Bardin (2011) para uma melhor elucidação dos dados. As análises prosseguiram de forma que em três livros foram encontrados experimentos sobre pilhas e baterias em uma visão ilustrativa/descritiva e no quarto livro foi encontrado uma forma de análise da composição de uma pilha, sendo classificada como experimentação investigativa. Com isso pudemos notar que a maior parte dos livros de química no PNLD aborda os conteúdos experimentais de pilhas e baterias de forma empírico-indutiva, com apenas um livro trazendo um tipo de abordagem investigativa.

PALAVRAS-CHAVE: Livro didático. Ensino de Química. Experimentação. 


\section{INTRODUÇÃO}

Apesar de muito presente no cotidiano das escolas, definir a função do livro didático (LD) em sala de aula é uma tarefa extremamente difícil, sendo tema de debate de diversos autores, como Lobato (2007), Munakata (1997), Romanatto (2009), Cassiano (2002), Frison et al. (2009), entre outros. Ainda, segundo Santos e Carneiro (2006), os temas mais frequentemente investigados nas pesquisas sobre livro didático de 1971 a 2003, são referentes a análise do conteúdo, metodologia, adequação, correção e, em menor escala, investiga-se o uso do livro na escola.

Moreira (1980) ressalta que sua função é descrita pela "[...] tentativa de condensar e simplificar num espaço mínimo e portátil o que se teria necessidade de conhecer e utilizar na atividade escolar" (apud MUNAKATA, 1997, p. 100).

Takahashi (1980) aponta que o LD deve ser uma ferramenta de apoio para os professores e alunos no processo de ensino e aprendizagem, afirmando que "[...] o livro didático é um instrumento auxiliar do professor e do aluno no processo de aprendizagem, veiculando o conteúdo da disciplina, de acordo com uma determinada metodologia" (apud MUNAKATA, 1997, p. 100). Vale ressaltar que apesar de ser o instrumento mais utilizado pelos docentes, o livro didático é uma ferramenta auxiliar e facilitadora, ou seja, outras ferramentas são necessárias no processo de construção do conhecimento (LOBATO, 2007).

O LD apresenta conteúdos definidos e apresentados progressivamente de forma didática e sequencialmente adequados ao processo cognitivo de construção do conhecimento, levando-se em consideração as etapas pedagógicas em que o aprendiz se encontra. Portanto, é uma proposta pedagógica que serve de apoio para o ensino. No Brasil, costuma-se produzir livros didáticos divididos em volumes seriados, e para o professor é dedicado um livro a parte, chamado de "livro do professor". Este pode ser considerado como uma cola, porém pode conter também textos de apoio, experimentos, sugestões de atividades, entre outros (MUNAKATA, 1997).

Neste sentido, reconhecendo os benefícios e utilidades do LD para a construção do conhecimento, o discutimos no contexto da educação brasileira, trazendo uma pequena parte histórica, algumas concepções dos documentos oficiais, as percepções dos professores acerca da sua utilização e por último apresentamos o Plano Nacional do Livro Didático (PNLD).

\section{LIVRO DIDÁTICO NO ENSINO DE CIÊNCIAS}

O desenvolvimento da escolarização no Brasil foi acompanhado pela utilização do livro didático. De acordo com Romanatto (2009), trata-se de um importante instrumento de trabalho do professor, sendo que no final do século XIX e início do século XX era considerado o único objeto educativo ao qual a criança tinha acesso. Entretanto, o cenário encontrado hoje é bem diferente do evidenciado.

Com a ascensão dos computadores e a necessária alfabetização científica e tecnológica, os Parâmetros Curriculares Nacionais (BRASIL, 1997) recomendam que os professores utilizem materiais diversificados para o tratamento dos conteúdos em sala de aula, pois esses materiais constituem maior fonte de 
informações para construção do conhecimento. Entretanto, o material mais comumente utilizado pelos docentes ainda é o livro didático (LOBATO, 2007).

Segundo Frison et al. (2009) o livro didático tem sido utilizado por alguns professores praticamente como único instrumento de apoio, se constituindo uma importante fonte de estudo e pesquisa. O autor também afirma que o LD é utilizado de diferentes formas, sendo que alguns professores seguem rigorosamente item a item e outros utilizam pouco ou quase nada por considerálo inadequado e desvinculado a realidade dos estudantes. Santos e Carneiro (2006) chamam a atenção para o fato de o livro didático ser utilizado apenas nas aulas de Ciências para resolução de exercícios.

Os livros didáticos produzidos nas últimas décadas e utilizados pelos professores em sala de aula possuem características que remetem à pedagogia tradicional, ou seja, apresenta-se um texto para o desenvolvimento do conteúdo, seguido de uma lista de exercícios com padrões pré-estabelecidos, normalmente voltados para o vestibular. Poucos são os livros que apresentam atividades variadas e com características inovadoras (SANTOS; CARNEIRO, 2006).

Segundo Frison et al. (2009), cabe ao professor estabelecer seus critérios de ensino para superar as limitações dos livros, que normalmente não contextualizam o saber e não desenvolvem uma abordagem histórica, filosófica e sociológica da Ciência.

Portanto, é imprescindível que professores e alunos trabalhem em conjunto utilizando o livro didático como um instrumento auxiliador, constituindo-se de uma "fonte viva de sabedoria, orientando processos de desenvolvimento dos estudantes" (NUÑEZ; RAMALHO, 2009, p. 01).

Em relação ao Ensino de Ciências, Frison et al. (2009) afirma que o LD tem função diferente das demais áreas do conhecimento, pois observa-se a aplicação de um método científico, como análise dos fenômenos, formulação de hipóteses e conclusões. $O$ autor também aponta que o livro didático deve ainda, propiciar a compreensão científica e filosófica, auxiliando na construção de um cidadão crítico e consciente de seu papel em sociedade.

No Brasil, as instituições de ensino têm autonomia para escolher as coleções de livros didáticos a serem utilizados como material de apoio. Entretanto, o ensino público, distribui os livros após passar por uma seleção criteriosa estabelecida pelo Ministério da Educação (MEC), que acontece a cada ciclo trienal, denominada Programa Nacional do Livro Didático (PNLD).

\section{PROGRAMA NACIONAL DO LIVRO DIDÁTICO}

Este programa abrange a escolha de livros didáticos que auxiliem no trabalho pedagógico dos professores, distribuindo diferentes coleções de livros didáticos aos alunos da educação básica.

Para que a escola receba estas coleções, é necessário que esteja inscrita no Censo Escolar do Instituto Nacional de Estudos e Pesquisas Educacionais Anísio Teixeira (INEP), que estima a quantidade necessária de livros para a instituição. Os livros são escolhidos após passar por análise que segue determinados critérios, explanados na seção seguinte deste trabalho. 
A partir de 1996 firmou-se o compromisso de distribuição universal para o Ensino Fundamental, dessa forma, o mercado editorial passou a produzir para suprir a demanda do governo. Em 2004 foi instituído o Programa Nacional do Livro Didático para o Ensino (PNLEM), dessa forma, garantiu-se a distribuição dos livros didáticos para todo o Ensino Básico. Ambos os Programas (PNLD e PNLEM) são financiados pelo Fundo Nacional de Desenvolvimento da Educação (FNDE). Segundo Oliveira (2014), o investimento do FNDE nos programas em 2009 chegou a R\$ 221 milhões, sendo assim, o livro didático passa a ser também uma mercadoria.

Hofling (2000) mostra que o PNLD traz consigo os princípios de democratização e maior acesso da população a educação, sendo assim, o programa é de grande importância e deve ser analisado e refletido acerca das prioridades sociais. Compreende-se aqui essa distribuição como obrigação do governo, entretanto, esse mercado editorial é responsável por uma grande movimentação financeira, e por muitas vezes o interesse privado se sobressai aos interesses públicos, influenciando também nos critérios de escolha do governo e quiçá dos professores.

Em relação a investigação dos Livros de Ciências, Megid Neto e Fracalanza (2006), apresentam dados das avaliações dos livros do PNLD e concluem que as melhorias têm se localizado nos aspectos gráficos e visual, na correção conceitual, eliminação de preconceitos ou estereótipos de raça, de gênero ou de natureza socioeconômica. Entretanto, ainda há muitos pontos a serem melhorados como a qualidade das atividades experimentais abordadas, a organização dos conteúdos, entre outros, fazendo-se importante a participação de professores e alunos no processo de escolha do livro didático, visto a importância deste no cenário político e econômico e nas pesquisas em Educação (OLIVEIRA, 2014).

\section{CRITÉRIOS DE AVALIAÇÃO DO LIVRO DIDÁTICO}

Atualmente as opções do LD são numerosas, havendo diversos exemplares no mercado. Para inserção no Ensino Médio eles passam pela avaliação do PNLD e quando aprovados, são disponibilizados para escolha do professor em sala de aula. Diante disso, a escolha deve ser criteriosa, considerando os variados aspectos pertinentes a sua concepção e produção (SANTOS; MÓL, 2007).

O PNLD estabelece alguns critérios de avaliação para a aceitação de um Livro Didático. Para ilustrá-los, escolhemos apresentar os critérios necessários para a aceitação de um livro didático de Química (LDQ):

- Imagens e ilustrações: A função da imagem é colaborar para a compreensão do texto, facilitando a construção do conhecimento do aluno (CASSIANO, 2002).

- Linguagem: a linguagem presente nos LD devem favorecer a compreensão dos conceitos científicos veiculados na obra, obedecendo a uma correção gramatical, léxica e sintática. $O$ texto didático deve primar pelo exercício correto da Língua Portuguesa, considerando as qualidades semânticas e sintáticas de um bom texto (SANTOS; MÓL, 2007). 
- Organização geral do livro: Deve-se atentar aos elementos prétextuais e pós-textuais. Faz-se necessária a utilização de glossário já que apresenta novas palavras e conceitos para os alunos (SANTOS; MÓL, 2007).

- Manual do Professor: é uma obra que visa auxiliar o professor em sua prática pedagógica (SANTOS; MÓL, 2007).

- Atividades práticas: tratando-se de Livro Didático de química, exige-se um caráter científico e experimental, esse critério não poderia ficar fora do LDQ (SANTOS; MÓL, 2007, grifo nosso).

- Contextualização: A contextualização do conteúdo químico no LDQ compreende uma melhoria da qualidade do Ensino de Química, como uma das formas de aquisição de dados da realidade, oportunizando ao aprendiz uma reflexão crítica do mundo e um desenvolvimento cognitivo, através de seu envolvimento de forma ativa, criadora e construtiva com os conteúdos abordados em sala de aula (SANTOS; MÓL, 2007).

Faz-se imprescindível o conhecimento do Guia do Programa Nacional do Livro Didático (PNLD), pois é tarefa de professores e da equipe pedagógica analisar as resenhas contidas no guia para escolher adequadamente os livros a serem utilizados no triênio. O livro didático deve ser adequado ao projeto políticopedagógico da escola; ao aluno e ao professor; e à realidade sociocultural das instituições. Os professores podem selecionar os livros a serem utilizados em sala de aula somente pela internet, no portal do Fundo Nacional do Desenvolvimento da Educação (FNDE).

Como podemos observar, um dos critérios de avaliação estabelecido pelo PNLD para análise do livro didático são as atividades práticas. O presente trabalho pretende analisar de que forma a experimentação está sendo apresentada no Ensino de Química, mais especificamente na temática de pilhas e baterias. Para esta análise, decidimos utilizar as categorias descritas por Oliveira e Soares (2010) e reelaboradas pelos pesquisadores a fim de classificar de que forma as atividades práticas estão dispostas nos livros do último triênio do PNLD (2015-2017).

\section{ELABORAÇÃO DO CORPUS DA PESQUISA}

O objetivo principal dessa pesquisa consiste em verificar e categorizar as atividades experimentais contidas nas seções do conteúdo de pilhas e baterias nos Livros didáticos de Química aprovados no PNLD de 2015. Justificamos a escolha, pois, segundo Fragal et al. (2011), os conteúdos de eletroquímica são frequentemente apontados por professores e estudantes como um dos assuntos que representam maior dificuldade no processo de aprendizagem dos alunos. Atribui-se a isso, distorções de conceitos básicos como ganhar e perder elétrons, além de falta de conhecimentos prévios de tabela periódica, $\mathrm{NO}_{x}$, entre outros.

Para isto, usamos a análise de conteúdo de Bardin (2011) para interpretar as informações coletadas.

A análise de conteúdo é uma metodologia que visa interpretar mensagens emitidas por diferentes meios de comunicação a partir de categorias que orientem 
a elaboração de inferências em relação a determinado assunto. É interessante ressaltar que estas categorias podem ser baseadas previamente em um referencial teórico (a priori) ou podem surgir de acordo com a análise advinda das informações, denominadas categorias emergentes. (BARDIN, 2011).

Para este trabalho, utilizamos como meio de comunicação os livros didáticos do PNLD 2015 (Quadro 1) e para a interpretação dos dados, reelaboramos as categorias a priori descritas por Oliveira e Soares (2010), que caracterizam os tipos de atividade experimental (Quadro 2). A reelaboração foi feita a partir da interpretação dos pesquisadores em que foi encontrada similaridade entre as categorias ilustrativas e descritivas, desta forma, foram agrupadas.

Quadro 1 - Livros didáticos selecionados para avaliação.

\begin{tabular}{c|c|}
\hline Codificação & \begin{tabular}{c} 
Referência \\
\hline LD1
\end{tabular} \\
\hline LD2 & $\begin{array}{r}\text { FONSECA, Martha Reis Marques da. Química. 3 v, São Paulo: } \\
\text { Ática, 2013. }\end{array}$ \\
\hline LD3 & $\begin{array}{r}\text { SANTOS, Wildson Luiz Pereira dos; MÓL, Gérson de. } \\
\text { Química Cidadã. 2. ed., 2 v, São Paulo: AJS, } 2013 .\end{array}$ \\
& MORTIMER, Eduardo Fleury; MACHADO, Andréa Horta. \\
& Química: ensino médio. 2. ed.,3 v, São Paulo: Scipione, \\
& 2013. \\
\hline LD4 & ANTUNES, Murilo Tissoni. Ser Protagonista - Química. 2. \\
& ed., 2 v, São Paulo: Edições SM, 2013. \\
\hline
\end{tabular}

Fonte: autoria própria (2017).

Quadro 2 - Tipos de atividades de Experimentação.

\begin{tabular}{c|c|}
\hline Atividade experimental & Descrição \\
\hline Demonstrativa & $\begin{array}{c}\text { O professor é o experimentador, sujeito principal. } \\
\text { Cabe ao aluno a atenção e o conhecimento do } \\
\text { material utilizado. O aluno observa, anota e classifica. }\end{array}$ \\
\hline Ilustrativa/Descritiva & $\begin{array}{c}\text { É realizada pelo aluno que manipula todo o material } \\
\text { sob a direção do professor. Serve para comprovar ou } \\
\text { re/descobrir leis }\end{array}$ \\
\hline Investigativa & $\begin{array}{c}\text { É realizada pelo aluno, que discute ideias, elabora } \\
\text { hipóteses e usa da experimentação para compreender } \\
\text { os fenômenos que ocorrem. A participação do } \\
\text { professor é dada na mediação do conhecimento. }\end{array}$ \\
\hline
\end{tabular}

Fonte: Adaptado de Oliveira e Soares (2010).

A experimentação demonstrativa segundo Gaspar e Monteiro (2005) é:

“(...) no ambiente escolar, pode referir-se a qualquer apresentação realizada em sala de aula, não vinculada ao uso do quadro-negro, como, por exemplo, a exibição de um filme ou de um slide, cuja atividade pode ser considerada pedagogicamente válida. No entanto, aqui usaremos o termo 'atividade de demonstração' ou 'atividade experimental de demonstração', para designar atividades experimentais que possibilitem apresentar fenômenos e conceitos de física, cuja explicação se fundamente na utilização de modelos físicos e priorize a abordagem qualitativa." (GASPAR; MONTEIRO, 2005, p. 231).

Esses autores se baseiam na teoria de Vygotsky para a atividade ou experimentação de cunho demonstrativo, levando em consideração que todo o conhecimento que esteja ligado às Ciências Sociais, Línguas, Matemática, Física, 
Química e Ciências Naturais em geral é considerado científico. Gaspar e Monteiro (2005) também afirmam que para a atividade demonstrativa experimental podemos frisar que:

\begin{abstract}
“(...) em sala de aula, particularmente quando relacionada a conteúdos de Física, apesar de fundamentar-se em conceitos científicos, formais e abstratos, tem por singularidade própria a ênfase no elemento real, no que é diretamente observável e, sobretudo, na possibilidade simular no microcosmo formal da sala de aula a realidade informal vivida pela criança no seu mundo exterior. Grande parte das concepções espontâneas, senão todas, que a criança adquire resultam das experiências por ela vividas no dia-a-dia, mas essas experiências só adquirem sentido quando ela as compartilha com adultos ou parceiros mais capazes, pois são eles que transmitem a essa criança os significados e explicações atribuídos a essas experiências no universo sócio-cultural em que vivem" (GASPAR; MONTEIRO, 2005, p. 232).
\end{abstract}

Com essa afirmação podemos entender que o método de experimentação demonstrativa deve ser testado pelo professor e perante os alunos, para que esses tenham ciência de que as suas concepções de mundo devem ser remediadas por um "adulto", o que no caso para a sala de aula de ciências deve-se ser entendido como o professor. Além disso, Gaspar e Monteiro (2005) explicam que a demonstração experimental acrescenta elementos de realidade e de experiências pessoais, podendo assim preencher uma lacuna cognitiva característica dos conceitos científicos.

A experimentação ilustrativa/descritiva é geralmente utilizada nas escolas após o conteúdo dado da disciplina, tendo como objetivo ilustrar e reforçar o conhecimento daquele assunto lecionado.

“O problema recai novamente na sistematização e problematização dos
resultados, tendo em vista que, a finalização da atividade experimental em si,
não é concluída com a experiência, mas pode servir de estratégia para que se
reforcem os conceitos previamente estabelecidos." (Taha et al., 2016, p. 142)

Taha et al. (2016) reforçam que a experimentação ilustrativa não deve ser apenas de modo a ilustrar um conteúdo, mas deve sim servir como uma estratégia para que o professor atraia a atenção dos alunos e que esse possa servir de reforço do conteúdo. "A atividade experimental ilustrativa pode ser significativa, desde que, empregada de maneira a reforçar a construção do conhecimento, desde que não tenha sido ilustrada apenas pela demonstração em si" (TAHA et al., 2016, p. 142).

Acreditamos que a atividade ilustrativa/descritiva utilizada de maneira inadequada possa reforçar as características de um ensino baseado no método empírico, caracterizado por Popper como "um método indutivo, e cujo critério de demarcação era o da verificabilidade" (apud MASSONI, 2005, p. 9). Nesse sentido, o método indutivo parte da observação para comprovação da teoria científica.

Massoni (2005) em sua monografia "Epistemologias do século XX", apoiada em importantes epistemólogos do século XX (Popper, Kuhn, Lakatos, Bachelard, entre outros), traz a concepção de que "o empirismo e o indutivismo estão superados como modelo de construção do conhecimento científico" (p. 92). Entretanto, não reduz o papel da observação como critério de comparação aos métodos experimentais, pois esse "diferencial garante a credibilidade da ciência" (p. 92). 
Massoni (2005) ao discutir as ideias de Lakatos, ressalta a importância das teorias ativas que pressupõe atividades mentais, classificando "o conhecimento autêntico associado as teorias ativas e na ideia de que conforme cresce a ciência, diminui o poder da evidência empírica" (p. 13). Ao discutir Bachelard, a autora argumenta que tanto o empirismo como o racionalismo, abordados ao extremo se constituem como um obstáculo epistemológico afirmando que deve haver uma "alternância entre o empirismo e o racionalismo, pois estas duas doutrinas estão ligadas, se complementam" (p. 25).

A experimentação investigativa é bastante defendida pelos pesquisadores do ramo de ensino de ciências (GIORDAN, 1999; GIL-PÉREZ, 1996; DELIZOICOV; ANGOTTI, 2000; BARATIERI, 2017; SCHNETZLER; ARAGÃO, 1995). Geralmente utilizada e defendida, a experimentação investigativa deve ser usada como ferramenta anterior a teoria que vai ser lecionada (COSTA, 2016).

Taha et al. (2016, p. 142) afirma que:

\begin{abstract}
"A atividade experimental investigativa tem o mesmo caráter da investigação científica: faz o levantamento do problema, elabora hipóteses, realiza o experimento para comprovar suas hipóteses e organiza os resultados para fazer suas próprias conclusões" (TAHA et al., 2016, p. 142)
\end{abstract}

Massoni (2005, p. 92) aponta que as epistemologias do século XX possuem em comum a identificação de que "a observação, a experiência, a experimentação não constituem fonte de conhecimento, pois a ciência é concebida constituindo-se hipóteses (conjeturas) e confrontando-as posteriormente, com o mundo real".

Sendo assim, os apontamentos epistemológicos de Massoni (2005) reforçam a ideia de que atividades pautadas apenas no empirismo e no indutivismo não são suficientes para a construção do conhecimento científico. Portanto, utilizar a atividade experimental investigativa além de ilustrar o conteúdo para o aluno, pode ser uma ferramenta útil para o aprimoramento do pensamento crítico e científico do estudante, sendo assim, é de suma importância a presença de experimentos investigativos nas aulas de ciências naturais do Ensino Médio brasileiro.

Com essa afirmação podemos notar que a atividade experimental investigativa vai além de ilustrar o conteúdo para o aluno.

Taha et al. (2016, p. 142) ainda diz que:

\begin{abstract}
“A experimentação investigativa também deve ter algum significado para o aluno, não devendo ser realizada apenas a prática pela prática, além disso, esse tipo de experimento deve ser concretizado pelo próprio aluno, ficando o professor apenas de mediador, permitindo que os alunos tenham liberdade na proposição de suas hipóteses. Para Soares $(2004$, p. 48) 'o manuseio é uma interação muito positiva, o que pode marcar em menor ou maior grau a pessoa" (TAHA et al., 2016, p. 142).
\end{abstract}

Podemos perceber a importância do professor no processo de ensinoaprendizagem utilizando a experimentação investigativa, tendo um papel além do professor conteudista. Muitas vezes o papel de professor mediador pode ser visto como na orientação de um pesquisador/orientador em um laboratório de pesquisa para com os seus orientandos, inserindo assim o aluno de Ensino Médio no meio 
acadêmico na busca da descoberta e em todos os prazeres que são envolvidos na questão de pesquisa e ensaios dentro de um laboratório de pesquisa.

\section{ANÁLISE DO LIVRO DIDÁTICO}

O LD1 aborda o conteúdo de pilhas e baterias no Capítulo 16 da unidade 5. Este capítulo é iniciado com uma contextualização ambiental, que remete ao descarte de lixo eletrônico e a relação com a saúde dos seres humanos. Após a contextualização o livro abordou os tópicos de oxidação e redução e reatividade dos metais, necessários para o entendimento do funcionamento de uma pilha. Em seguida, a atividade experimental classificada como ilustrativa/descritiva está apresentada na página 268, conforme a Figura 1 a seguir:

Figura 1 - Experimentos do LD1

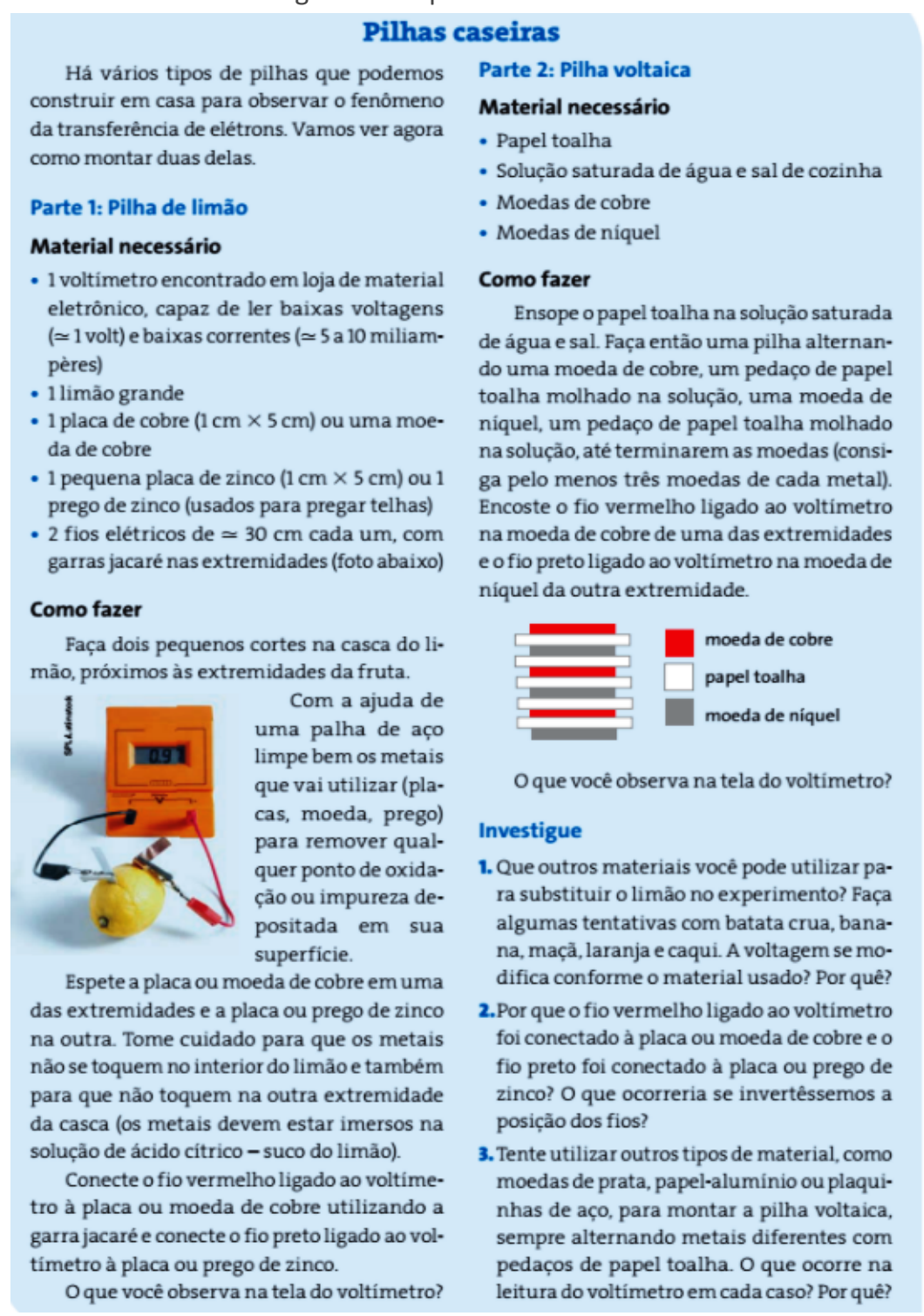

Fonte: Reis (2013, p. 268). 
É interessante observar que o livro sugere a realização de dois experimentos nesta seção, intitulados "Pilha de limão" e "Pilha voltaica".

A classificação dos experimentos se deu pela correspondência da descrição da categoria com o texto descrito nas atividades experimentais. Como podemos verificar, a atividade pode ser realizada opcionalmente com a supervisão do professor, ou seja, destaca que o aluno pode realizá-lo individualmente. No texto pode-se observar a sugestão para realização da atividade extraclasse.

Ao final da atividade experimental a autora sugere mudanças nos materiais utilizados na prática, para que se comprove os tópicos relacionados ao funcionamento de uma pilha (reatividade, eletrólitos e condutividade), o que reafirma a escolha pela categoria ilustrativo/descritiva para esta atividade experimental.

Prosseguindo as análises, o LD2, excepcionalmente traz o conteúdo de pilhas e baterias abordadas em um livro didático utilizado no $3^{\circ}$ ano do Ensino Médio, enquanto os demais livros trazem este conteúdo no segundo volume da coleção, ou seja, espera-se que seja abordado no $2^{\circ}$ ano do Ensino Médio. $O$ experimento neste livro está situado na Unidade 2, no Capítulo 7, que aborda exclusivamente o conteúdo relacionado às pilhas e eletrólise, porém analisamos apenas a atividade prática relacionada às pilhas, por ser o foco principal deste trabalho. Este experimento foi colocado após a conscientização em relação ao descarte e um breve histórico das pilhas e baterias.

A atividade proposta tem um roteiro previamente elaborado para que os alunos apenas executem os procedimentos, como por exemplo, a utilização de diferentes metais em diferentes soluções aquosas (Figura 2), a fim de observar o comportamento final do sistema eletroquímico. Esta percepção foi reforçada pela colocação dos autores a concentração das soluções a serem utilizadas nesta prática sem que haja orientação aos alunos de como preparar esta solução. Portanto, esta atividade prática foi considerada ilustrativa/descritiva. 


\section{Quimica na escola \\ Consulte as normas de segurança no laboratório, na última página deste livro.}

\section{Líquidos podem atacar metais?}

Este experimento poderá ser feito em grupo, na sala de aula ou no laboratório.

\section{Material}

- 8 béqueres (ou copos de vidro)

- 1 esponja de palha de aço fina dividida em 4 pedaços

- 4 clipes metálicos

- água destilada (água para bateria)

- solução de sacarose $1 \mathrm{~mol} / \mathrm{l}$ (açúcar)

- solução de cloreto de sódio $1 \mathrm{~mol} / \mathrm{L}(\mathrm{NaCl})$

- solução de sulfato de cobre $1 \mathrm{~mol} / \mathrm{L}\left(\mathrm{CuSO}_{4} \cdot 5 \mathrm{H}_{2} \mathrm{O}\right)$

\section{Procedimento}

1. Marque os béqueres com os seguintes rótulos: 1a, 1b, 2a, 2b, 3a, 3b, 4a e 4b.

2. Coloque liquido em cada béquer, até a metade, de acordo com a numeraçăo: 1 - água destilada; $\quad 3$ - soluçăo de doreto de sódio;

2- solução de sacarose; $\quad$ 4- solução de sulfato de cobre.

3. Desenhe em seu caderno uma tabela como a seguinte.

\begin{tabular}{|l|c|c|c|c|}
\hline \multirow{2}{*}{ Liquido } & \multicolumn{2}{c|}{ Palha de aço } & \multicolumn{2}{c|}{ Clipes } \\
\cline { 2 - 5 } & antes & depois & antes & depois \\
\hline 1. Água destilada & $\equiv \equiv \equiv \equiv$ & $\equiv \equiv \equiv \equiv$ & $\equiv \equiv \equiv \equiv$ & $\equiv \equiv \equiv \equiv$ \\
\hline 2. Açúcar aquoso & $\equiv \equiv \equiv \equiv$ & $\equiv \equiv \equiv \equiv$ & $\equiv \equiv \equiv \equiv$ & $\equiv \equiv \equiv \equiv$ \\
\hline 3. NaCl aquoso & $\equiv \equiv \equiv \equiv$ & $\equiv \equiv \equiv \equiv$ & $\equiv \equiv \equiv \equiv$ & $\equiv \equiv \equiv \equiv$ \\
\hline 4. CuSO aquoso & $\equiv \equiv \equiv \equiv$ & $\equiv \equiv \equiv \equiv$ & $\equiv \equiv \equiv \equiv$ & $\equiv \equiv \equiv \equiv$ \\
\hline
\end{tabular}

4. Em cada recipiente com a letra a coloque um pedaço da palha de aço e nos recipientes com a letra b, um clipe. Observe e anote características dos liquidos e dos sólidos nas colunas antes.

5. Observe por 20 minutos e anote características dos liquidos e dos sólidos nas colunas depois.

\section{Destino dos resíduos}

1. Os materiais liquidos dos béqueres 1,2 e 3 desta atividade podem ser descartados no sistema de coleta de esgoto e os residuos sólidos, no lixo.

2. 0 material liquido do béquer 4 deve ser acondicionado em embalagem compativel, limpa eà prova de vazamento, para ser reutilizado em outras atividades práticas. 0 residuo sólido deste béquer deve ser descartado no lixo.

\section{Análise de dados}

1. Em quais sistemas houve variação de caracteristicas?

2. Como você pode explicar microscopicamente as alteraçōes observadas?

3. Como você justifica as diferenças observadas entre os sistemas?

4. 0 que têm em comum os liquidos que se modificaram e os liquidos nos quais não se observaram modificaçōes? Fonte: Santos e Mól (2013, p. 246).

O LD3 é sistematizado de forma diferente dos demais, apresentando diversas atividades e textos para compreender o funcionamento das pilhas, procedimentos para realizar o cálculo da diferença de potencial, reatividade dos metais. Podemos constatar que não há uma abordagem experimental semelhante as analisadas anteriormente, visto que não há um roteiro em que os alunos executem sequencialmente e sim um roteiro norteador, conforme apresentado na Figura 3. 
Figura 3 - Atividade experimental do LD3

Vocês já devem ter percebido a diferença, no aspecto externo, entre uma pilha nova e uma usada, ao verificar, eventualmente, o vazamento de um material líquido e viscoso da pilha velha. Mesmo quando isso não é visível, contudo, é possível que esse material já tenha sido formado e esteja retido dentro da pilha, por causa da embalagem. Portanto, muito cuidado com vazamentos súbitos, ao trabalhar com pilhas usadas. Para enriquecer suas observações, trabalhem com uma pilha nova e uma usada.

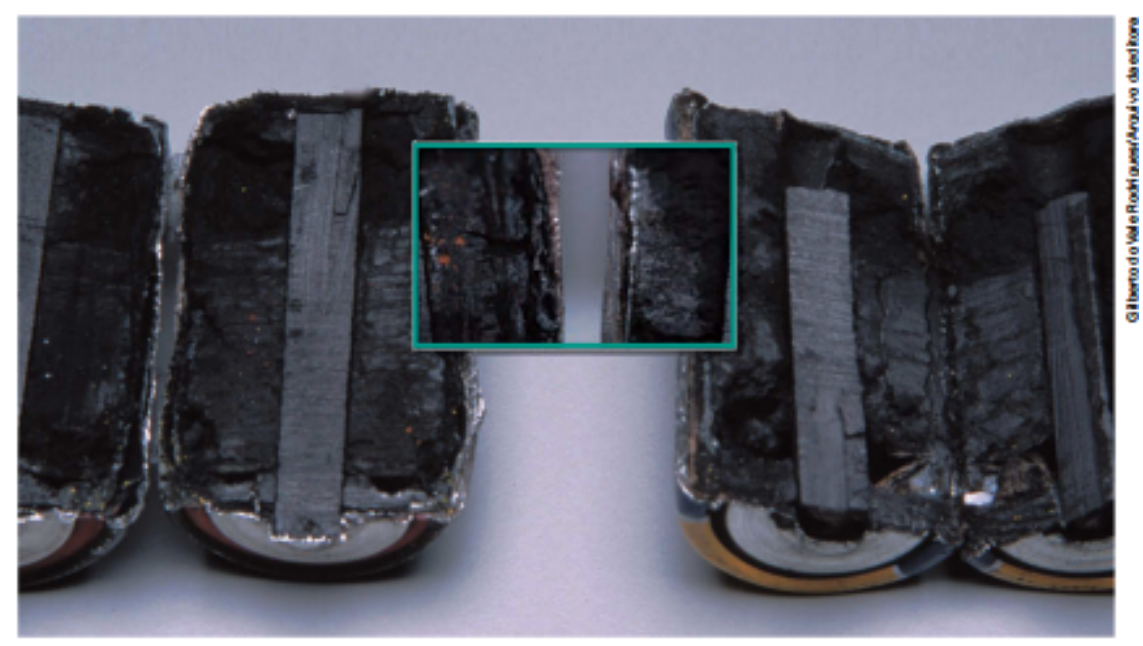

Figura 5.42

Pihas usadas e novas apresentam aspectos diferentes.

\section{Material}

Pilhas não alcalinas novas e usadas, jornal, alicates com ponta de corte, luvas grossas de borracha.

Preparem, em uma mesa ou equivalente, um espaço forrado de jornal.

A30 Observem o corpo da pilha. Ele tem a forma de um cilindro com uma das bases chatas. Fica mais fácil começar a abrir a pilha pela sua parte oposta, que apresenta uma protuberância. Tentem, com a ponta do alicate, levantar a bainha da capa metálica que contorna a pilha. Aqui a habilidade é mais importante do que a força.

A31 Exponham as partes da pilha aberta e façam um desenho das seções que a compõem, observando rigorosamente as partes. Com base nas informações do texto a seguir [ 0 s constituintes da pilha comum], identifiquem todas as partes do desenho que fizeram.

A32 Terminada a operação, recolham separadamente as partes da pilha, colocando-as em recipientes específicos. Cada material deve ter um encaminhamento. Perguntem ao professor como fazê-lo.

Fonte: Mortimer e Machado (2013, p. 230).

Assim, o objetivo não foi a construção de uma pilha e sim a análise da sua 
primeiramente por se tratar de uma atividade que consiste na utilização de ferramentas para observar o interior de uma pilha. Os autores descrevem que essa tarefa pode ser uma forma de relacionar a atividade com as informações previamente demonstradas nos textos conforme eventuais dúvidas possam surgir (MORTIMER; MACHADO, 2013). Portanto, exige que o aluno seja o principal responsável pela aprendizagem do conteúdo. Essa atividade não é apenas comprobatória de teorias ou leis.

O LD3 se diferencia dos demais por trazer uma abordagem experimental investigativa, sendo uma forma de "levar o aluno a participar de seu processo de aprendizagem, sair de uma postura passiva e começar a perceber e agir sobre o seu objeto de estudo" (AZEVEDO, 2004, p. 22).

Por fim, o LD4, que aborda o conteúdo de pilhas e baterias eletroquímicas no capítulo 4, expõe a teoria em textos sequencialmente ordenados, em seguida orienta a resolução de exercícios e propõe então a realização da atividade experimental.

O experimento compreende a construção de uma pilha utilizando limões similar a do LD1, propondo aos alunos a montagem de um sistema que possibilite a verificação da existência de corrente elétrica ao utilizar um eletrólito e metais condutores, sendo esta uma atividade executada com a finalidade de reforçar a teoria aprendida, desta forma, categorizamos como uma atividade experimental descritiva/ilustrativa.

\section{CONCLUSÃO}

A análise de livro didático é muito importante para avaliar certos aspectos de conteúdo, exercícios e experimentos passados para os alunos da Educação Básica, pois o livro didático é uma ferramenta bastante utilizada pelos professores das escolas do nosso país. Com ela podemos realizar uma análise crítica e mais detalhada sobre determinado aspecto, tendo em vista uma possível contribuição para as práticas educativas.

Com a análise dos quatro livros didáticos de química aprovados no PNLD 2015 foi possível observar que há semelhanças e diferenças entre eles a respeito da experimentação de pilhas e baterias.

O LD1 apresentou dois tipos de experimentos referentes ao conteúdo de pilhas e baterias: um experimento referente a construção de uma pilha com limões e outro referente a construção de uma pilha voltaica, sendo ambos de forma ilustrativa/descritiva para reforçar o conteúdo aplicado. O LD4 também abordou o experimento da pilha com limões da forma ilustrativa/descritiva para reforço da teoria.

Algo que nos chamou atenção foi o fato de os autores do LD2 abordarem o conteúdo de pilhas e baterias no livro didático do $3^{\circ}$ ano do Ensino Médio, o que despertou curiosidade, pois todos os outros livros do PNLD abordaram o conteúdo no volume 2. Entretanto, o LD2 também teve como abordagem experimental a ilustrativa/descritiva.

Por fim, o LD3 abordou o experimento de pilhas e baterias de forma que não há um roteiro pré-determinado para o aluno/professor seguirem, mas sim um 
roteiro norteador que pode ser usado para a experimentação do conteúdo, esse experimento não propôs a construção de uma pilha, mas a análise de sua composição.

Por meio das análises realizadas, percebemos que os livros ainda trabalham uma abordagem empírica/indutivista, pautada na observação e execução dos experimentos para comprovação dos resultados esperados. Assim, o tipo de abordagem mais recorrente nos livros do PNLD referente ao conteúdo experimental de pilhas e baterias pode não ser dos mais motivadores para que o aluno desperte o seu interesse pela ciência e pelo conteúdo em si. 


\title{
Analyzing the electrochemistry experimentation in chemistry text books
}

\begin{abstract}
The objective of this work was to verify and categorize the experimental activities contained in the sections of the contents of cells and batteries in four chemistry text books. The content analysis of Bardin (2011) was used for a better elucidation of the data. In three books were found experiments on cells and batteries in an illustrative/descriptive vision and in the fourth book was found a form of analysis of the composition of a cell, being classified as investigative experimentation. With this, we can notice that most of the chemistry text books has expermentations about battery and battery cells in an empirical-inductive way, with only one book bringing a kind of investigative approach.
\end{abstract}

KEYWORDS: Textbook. Chemistry teaching. Experimentation. 


\section{AGRADECIMENTOS}

À fundação CAPES e às Universidades Estaduais de Londrina (UEL) e de Maringá (UEM).

\section{REFERÊNCIAS}

ANTUNES, M. T. Ser Protagonista - Química. 2. ed., 2 v, São Paulo: Edições SM, 2013.

AZEVEDO, M. C. P. S. Ensino por investigação: problematizando as atividades em sala de aula. In: CARVALHO, A. M. P. (Org.). Ensino de ciências: unindo a pesquisa e a prática. São Paulo: Pioneira Thomson Learning, 2004. p. 19-33.

BECKER, Fernando. O caminho da aprendizagem em Jean Piaget e Paulo Freire: Da ação à operação. Petrópolis, RJ: Vozes, 2010.

BRASIL. Fundo Nacional de desenvolvimento da educação. Programa Nacional do Livro Didático - PNLD. Disponível em: <http://www.fnde.gov.br/programas/livrodidatico> Acesso em: 01 nov. 2016.

, Ministério da Educação. Parâmetros Curriculares Nacionais - PCN CIÊNCIAS 1997. Brasília: 1997.

BARATIERI, S. M.; BASSO, N. R. S.; BORGES, R. M. R.; ROCHA FILHO, J. B. Opinião dos estudantes sobre a experimentação em química no Ensino médio.

Experiências em Ensino de Ciências, v. 3, n. 3, p. 19-31, 2008. Disponível em: < http://if.ufmt.br/eenci/?go=artigos\&idEdicao=20 > Acesso em: 2 de abril 2017

BARDIN, L. Análise de Conteúdo. São Paulo: Edições 70, 2011

CASSIANO, W. S. Análise de imagens em livros didáticos de Física. 2002. 126 p. Dissertação (Mestrado em Educação) - Faculdade de Educação, Universidade de Brasília, Brasília. 2002.

DELIZOICOV, D.; ANGOTTI, J. A. P. Metodologia do ensino de Ciências. 6. ed. São Paulo: Cortez, 2000.

FONSECA, M. R. M. da. Química. 3 v, São Paulo: Ática, 2013. 
FRACALANZA, H; MEGID, J (Org.). O Livro Didático de Ciências no Brasil. Campinas: Komedi, 2006.

FRAGAL, V. H.; MAEDA, S. M.; PALMA, E. P.; BUZATTO, M. B.; RODRIGUES, M. A.; SILVA, E. L. Uma proposta alternativa para o ensino de eletroquímica sobre a relatividade de metais. Química Nova na Escola, v. 33, n. 4, 2011.

FRISON, M; VIANNA, J; CHAVES, J; BERNARDI, F. Livro didático como instrumento de apoio para a construção de propostas de ensino de Ciências Naturais. Encontro Nacional de Pesquisa em Educação em Ciências. Florianópolis, Nov/2009.

GASPAR, A; Monteiro, C. Atividade Experimentais de Demonstrações em Sala de Aula: Uma Análise Segundo o Referencial da Teoria de Vygotsky. Investigação em Ensino de Ciências. V. 10(2), p 227-254, 2005. Disponível em: <

www.if.ufrgs.br/ienci/artigos/Artigo_ID130/v10_n2_a2005.pdf > Acesso em: 5 de maio 2017

GIL-PÉREZ, D.; VALDÉS, P. La orientación de las prácticas de laboratorio como investigación: un ejemplo ilustrativo. Enseñanza de las Ciencias, v. 14, n. 2, p. 155-163, 1996. Disponível em:

<http://www.raco.cat/index.php/Ensenanza/article/view/21444 > Acesso em: 1 de abril 2017

GIORDAN, M. O papel da Experimentação no ensino de ciências. Química Nova na Escola, n. 10, p. 43-49, 1999. Disponível em: <

qnesc.sbq.org.br/online/qnesc10/pesquisa.pdf > Acesso em: 1 de abril 2017

HOFLING, E. de M. Notas para discussão quanto à implementação de programas de governo: em foco o Programa Nacional do Livro Didático. Rev. Educação e Sociedade, v. 21, n. 70, p.159-170, 2000.

LOBATO, A. A abordagem do efeito estufa nos livros de química: uma análise crítica. Monografia de especialização. Belo Horizonte, 2007, CECIERJ.

MORTIMER, E. F.; MACHADO, A. H. Química: Enino Médio. 2. ed., 3 v, São Paulo: Scipione, 2013.

MUNAKATA, K. Produzindo livros didáticos e paradidáticos. 1997. Tese (Doutorado em história e filosofia da educação) - Pontifícia Universidade Católica de São Paulo, São Paulo, 1997. Disponível em: radid\%C3\%A1ticos>. Acesso em: 14 nov. 2016. 
NÚÑEZ, B; RAMALHO, B. A formação continuada dos professores que ensinam ciências naturais: pressupostos e estratégias. In: JÓFILI, Zélia; ALMEIDA, Argus Vasconcelos de (Org.). Ensino de Biologia, meio ambiente e cidadania: olhares que se cruzam. Recife: Editora da UFRPE, 2009.

OLIVEIRA, L. Programa nacional do livro didático (PNLD): Aspectos históricos e políticos. 2014. Disponível em: <http://alb.com.br/arquivomorto/edicoes_anteriores/anais17/txtcompletos/sem18/COLE_2079.pdf> Acesso em: 20/10/2016.

OLIVEIRA, N; SOARES, M. As atividades de experimentação investigativa em ciência na sala de aula de escolas de ensino médio e suas interações com o Iúdico. In: ENEQ, 15, 2010. Brasília. Resumos... Brasília: UnB, 2010. 12.

ROMANATTO, M. O Livro Didático: alcances e limites. 2009. Disponível em: http://www.sbempaulista.org.br/epem/anais/mesas_redondas/mr19Mauro.doc. Acesso em: 19/10/2016.

SANTOS, S.; MÓL, G. Planilha para avaliação de Livros Didáticos de Química para o Ensino Médio: um instrumento de auxílio ao professor. In: Atas do VI Encontro Nacional de Pesquisa em Educação em Ciências. Florianópolis, 2007.

SANTOS, W. L. P. dos; MÓL, G. de. Química Cidadã. 2. ed., 2 v, São Paulo: AJS, 2013

SANTOS, W.; CARNEIRO, M. Livro didático de ciências: Fonte de informação ou apostila de exercícios? Contexto \& Educação, v.21, n.76, p.201-222, 2006.

SCHNETZLER, R. P.; ARAGÃO, R. M. R. Importância, Sentido e Contribuições de Pesquisas para o Ensino de Química. Química Nova na Escola. n.1, p. 27-31, 1995. Disponível em: <qnesc.sbq.org.br/online/qnesc01/pesquisa.pdf> Acesso em: 1 de abril de 2017

TAHA, M. S; LOPES, C. S. C; Soares, E. L. FOLMER, V. Experimentação como Ferramenta pedagógica para o ensino de ciências. Experiências em Ensino de Ciências, v. 11, n. 1, p 138-154, 2016. Disponível em: <if.ufmt.br/eenci/artigos/Artigo_ID305/v11_n1_a2016.pdf>. Acesso em: 05 de maio 2017 
Recebido: 20 set. 2017

Aprovado: 20 jan. 2018

DOI: $10.3895 /$ actio.v3n1.6846

Como citar:

SANTOS, M. C. G.; BALDAQUIM, M. J.; VIDA LEAL, L. P. Analisando a temática experimentação no ensino de Química no conteúdo de eletroquímica dos livros didáticos aprovados no PNLD 2015. ACTIO, Curitiba, v.

3, n. 1, p. 205-223, jan./abr. 2018. Disponível em: <https://periodicos.utfpr.edu.br/actio>. Acesso em: XXX

Correspondência:

Mateus Carneiro Guimarães dos Santos

Universidade Estadual de Maringá, Avenida Colombo, 5790, bloco F67, sala 007, CEP: 87020-900, Maringá,

Paraná, Brasil.

Direito autoral: Este artigo está licenciado sob os termos da Licença Creative Commons-Atribuição 4.0

Internacional.

(c) (1) 